\title{
Interaction Between Subtropical and Polar-Front Jet Stream
}

\author{
By \\ E.R. Reiter \\ Department of Atmospheric Science \\ Colorado State University \\ Fort Collins, $\mathrm{CO}$ \\ and \\ L.F. Whitney \\ Meteorological Satellite Laboratory \\ National Environmental Satellite Center \\ ESSA \\ Suitland, Md
}

Department of Atmospheric Science

Colorado State University

Fort Collins, Colorado

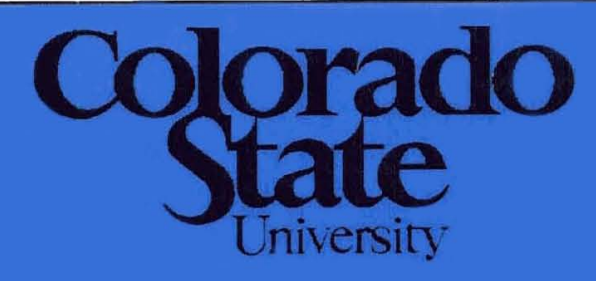

Department of
Atmospheric Science

Paper No. 147 
Reprinted from MONTHLY WEATHER REVIEW, Vol. 97, No. 6, June 1969, pp. 432-438.

\title{
INTERACTION BETWEEN SUBTROPICAL AND POLAR-FRONT JET STREAM
}

\author{
E. R. REITER \\ Department of Atmospheric Science, Colorado State University, Fort Collins, Colo. \\ L. F. WHITNEY \\ Meteorological Satellite Laboratory, National Environmental Satellite Center, ESSA, Suitland, Md. \\ ABSTRACT

\begin{abstract}
By means of satellite photographs originally analyzed by Oliver et al., it is shown that the polar-front jet stream and the subtropical jet stream do not behave as entities in regions where they approach each other closely. A crossover of flow is observed whereby the subtropical current overrides, and merges with, the polar-front jet.
\end{abstract}

\section{INTRODUCTION}

In a recent study Oliver, Anderson, and Ferguson (1964) have described the observation of dark bands in TIROS $\mathrm{V}$ and VI cloud photographs that were associated with jet streams at tropopause level. Since cloud heights on the south side of these bands were appreciably higher than on the north side (ca. $35,000 \mathrm{ft}$ as compared with ca. $7,000 \mathrm{ft}$, according to aircraft observations), the conclusion was reached that under favorable conditions a highlevel cirrus deck may cast a shadow on low-level clouds, creating a dark band wide enough to appear on TIROS photographs.

From a comparison of aircraft observations with those taken from TIROS, it is evident that the cirrus bank shows large horizontal extent and has a sharply defined edge. Findings by Oliver et al. (1964) using satellite pictures agree well with those by Kadlec $(1963,1964)$ using visual and photographic cloud surveys from commercial airline flights.

Figure 1 shows one of Kadlec's cirrus distribution models, which he describes as follows:

"The northern polar jet stream is oriented in a trough-ridge pattern while the southern or subtropical jet stream is curved anticyclonically. The average distance across the cirrus pattern varies from approximately $400 \mathrm{n}$.mi. in the area of formation east and south of the upper trough to between 1,000 and $1,500 \mathrm{n}$.mi. in the ridge. This extensive area of cloud cover occurs when the two jet streams converge to within $300 \mathrm{n}$.mi. in the trough area. If the separation between the two jet streams is $400 \mathrm{n}$.mi. or more, two separate areas of cirrus may form with clear skies occurring between the two jet streams near and downwind of the ridge line. ..."

Thus, the condition for establishment of the observed cirrus distribution seems to be the merger and subsequent splitting of polar front (PFJ) and subtropical jet streams (STJ), if we were to adopt-at least for the moment-the classical nomenclature of describing the flow pattern near tropopause level.

Galloway (1958, 1963) and McIntyre (1958), in describing the Canadian three-front, three jet-stream model, allow for similar weather patterns in which jets associated with differences between $\mathrm{cA}, \mathrm{mA}, \mathrm{P}$, and $\mathrm{T}$ air masses approach each other closely.

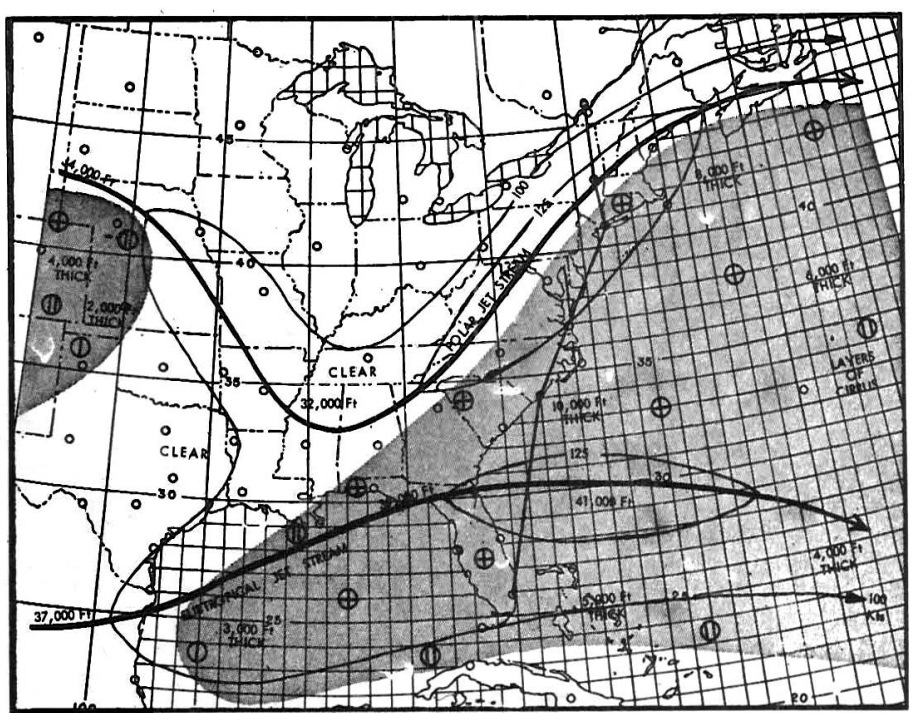

Figure 1.-Schematic cirrus distribution (shaded area) near merging jet streams. Jet axes indicated by heavy lines and isotachs by thin lines (after Kadlec, 1963).

\section{CROSSOVER OF JET STREAMS}

In a situation similar to that in the Kadlec model, Reiter and Nania (1964) have given evidence that trajectories on isentropic surfaces do not support the classical model of confluence and diffluence of PFJ and STJ. From isentropic analyses published in that paper, it appears that air in the northwesterly jet branch submerged beneath warm air traveling within the southwesterly jet. The separation of the two currents is marked by a sharp line of directional cyclonic shear. Vertical cross-sections through the region are characterized by a relatively shallow zone, sloping from north to south, in which the wind backs sharply with height (as much as $65^{\circ}$ within a $100-\mathrm{mb}$ layer). It is within this layer of directional wind shear that the observed clear-air turbulence (CAT) occurred. The southwesterly jet overrides the northwesterly one, and the air within it ascend while doing so. Cyclonic shears are very strong in this southwesterly flow east of the trough. This apparent crossover of flow has prompted 


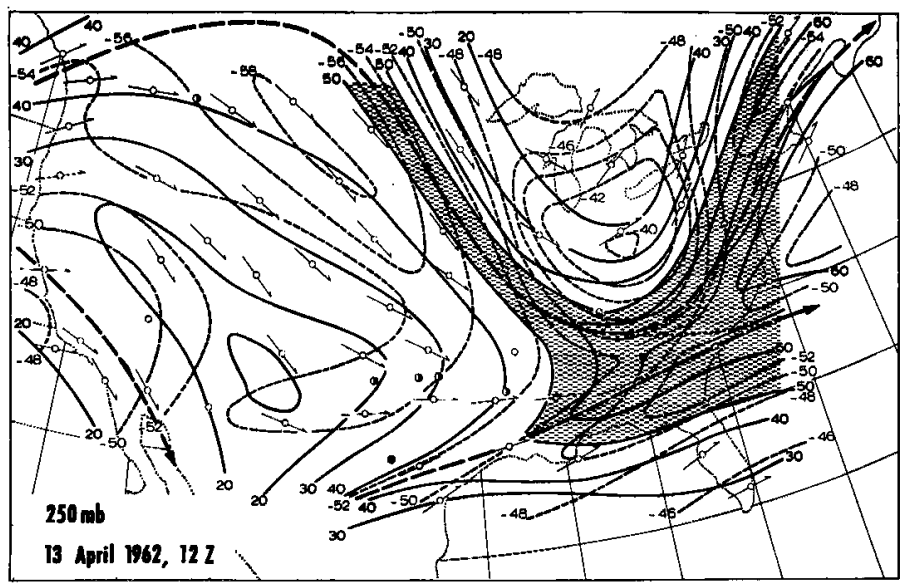

Figure 2.-250-mb isotachs (solid lines, $\mathrm{m} / \mathrm{sec}$, areas with $>50$ $\mathrm{m} / \mathrm{sec}$ shaded) and isotherms (dashed lines, ${ }^{\circ} \mathrm{C}$ ), Apr. 13, 1962, 1200 GMT. Jet axes indicated by heavy dashed lines with arrows. Dotted lines show crossover of jet axes (after Reiter and Nania, 1964).
Reiter and Nania (1964) to mark jet axes as indicated by dotted lines in figure 2.

Satellite photographs have also tended to support this configuration. Where two parallel or converging jet streams might normally be analyzed within about 300 n.mi. of each other, Whitney, Timchalk, and Gray (1966) have suggested instead a single jet stream or isotach maximum axis in agreement with the well-defined poleward edge of jet-associated cirrus seen in satellite pictures. Actually, while one jet axis may be apparent in the horizontal, there may be two, one superimposed on the other, in a vertical cross-section (Reiter et al., 1961). The object of this paper is to expand on this concept by providing additional documentation.

\section{JET STREAM OF NOVEMBER 20, 1962}

Figure 3, reproduced from the paper by Oliver et al. (1964), shows a mosaic of TIROS-VI pictures on Nov. 20,

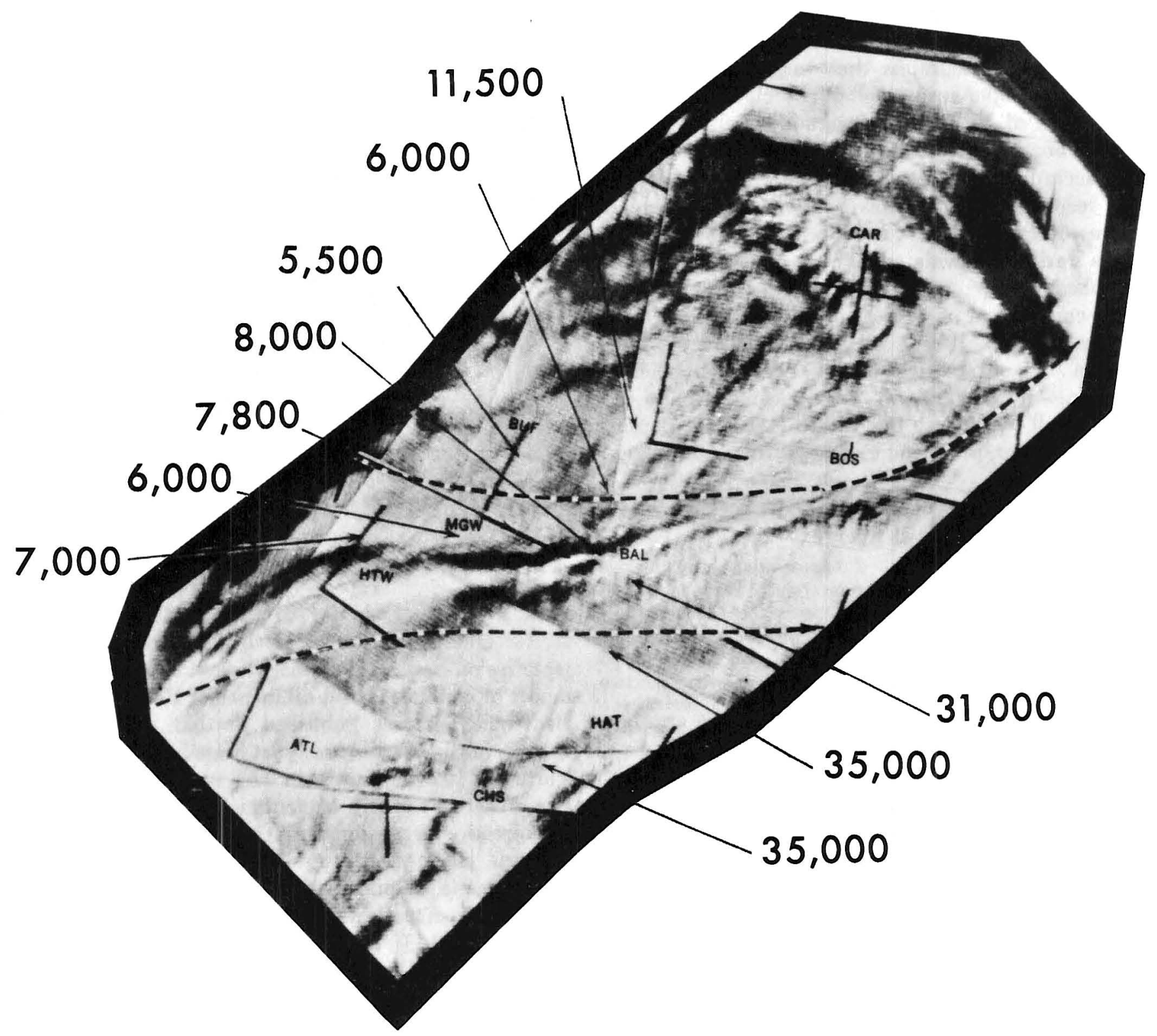

Figtre 3.- A mosaic of Pass 0922, TIROS VI, 1355 GMT, Nov. 20, 1962. Height of cloud tops reported in feet. Dashed lines indicate 200-mb jet-stream positions as analyzed by the National Meteorological Center. A dark streak (shadow band) is clearly visible between the two jet axes (after Oliver et al., 1964). 


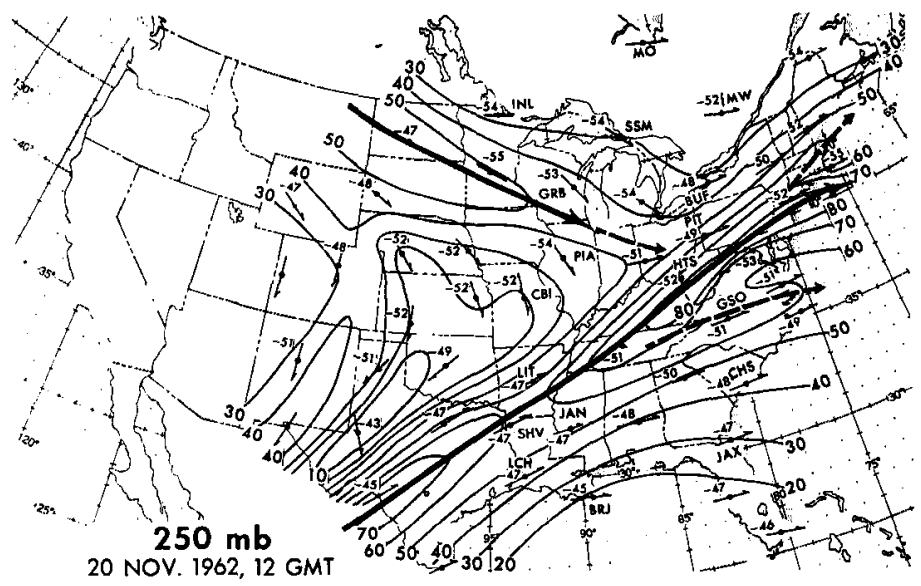

Figure 4.-250-mb isotachs (m/sec), Nov. 20, 1962, $1200 \mathrm{GMT}$. Stations used in subsequent cross sections are identified by call letters. Main jet axis has been analyzed in accordance with the edge of the cirrus cloud bank. Temperatures in ${ }^{\circ} \mathrm{C}$ are given numericaily.

1962, 1355 GMT. Observed cloud heights are given along the edge of the cloud photographs. The dark "shadow" line is clearly visible, extending approximately from Huntington (HTS), W. Va., beyond Boston (BOS), Mass. Especially in the Baltimore (BAL) region, the abrupt change in cloud heights is well substantiated by pilot reports, as noted by Oliver et al. TIROS V, passing the region at 1448 on the same day, gave further proof of the shadow line in an essentially unchanged position.

Figure 4 shows 250-mb winds and temperatures for Nov. 20, 1962, 1200 GMT. A jet branch from the northwest is merging with a strong southwesterly jet-stream flow. This merger takes place in the region near Pittsburgh (PIT) and Huntington (HTS on fig. 4 and HTW on fig. 3), where only one jet axis has been indicated in figure 4 . It was in this confluent region that Oliver et al. discovered the cloud-shadow band described above. In their analysis, however, two almost parallel jets within separate contour channels are indicated (fig. 3), corresponding to the dashed "jet fingers" in figure 4.

In the latter diagram a well-marked shear line is located over the south-central United States. The region west of the shear line is characterized by clear skies (fig. 5). Precipitation is observed in the right rear quadrant of the strong jet maximum that is produced by the merger of the two jet branches, in line with the vorticity distribution and the resulting upper divergence pattern.

Further inspection of the 250-mb chart shown in figure 4 reveals a region of diffluence between PFJ and STJ (using classical nomenclature) over the northeast coast of the United States. This diffluent area lies over a highpressure cell. The latter is located to the rear of a quasistationary frontal system that has advanced into the southeastern United States. This high-pressure system, which migrated slowly eastward, was produced by a cold outbreak and is not part of the subtropical high-pressure

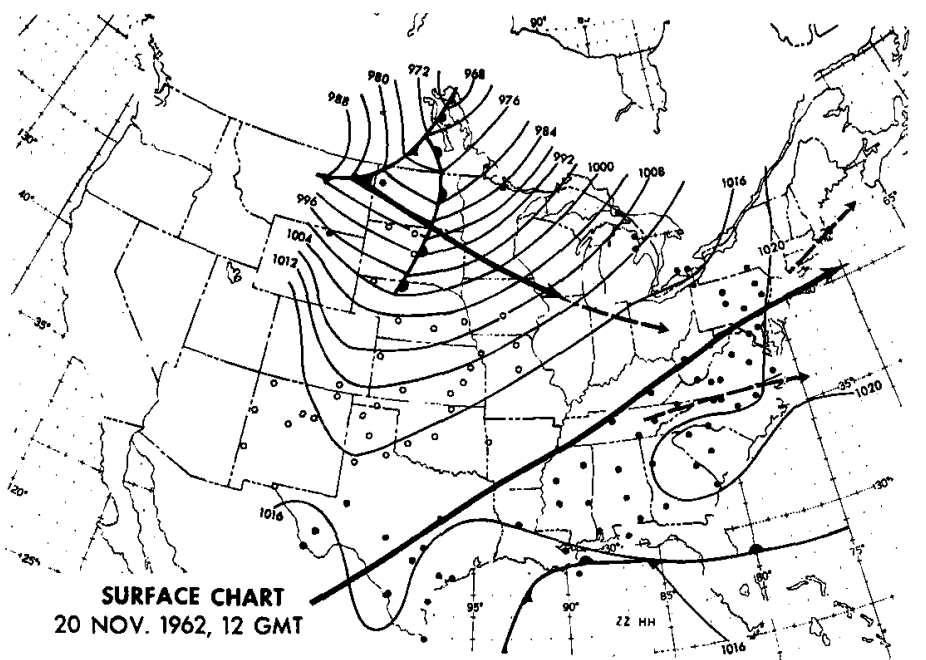

Figure 5.-Surface chart, Nov. 20, 1962, 1200 GMT. Open circles indicate clear skies; black circles, precipitation; heavy solid lines, major jet streams; heavy dashed lines, wind maxima; and thin solid lines, surface isobars.

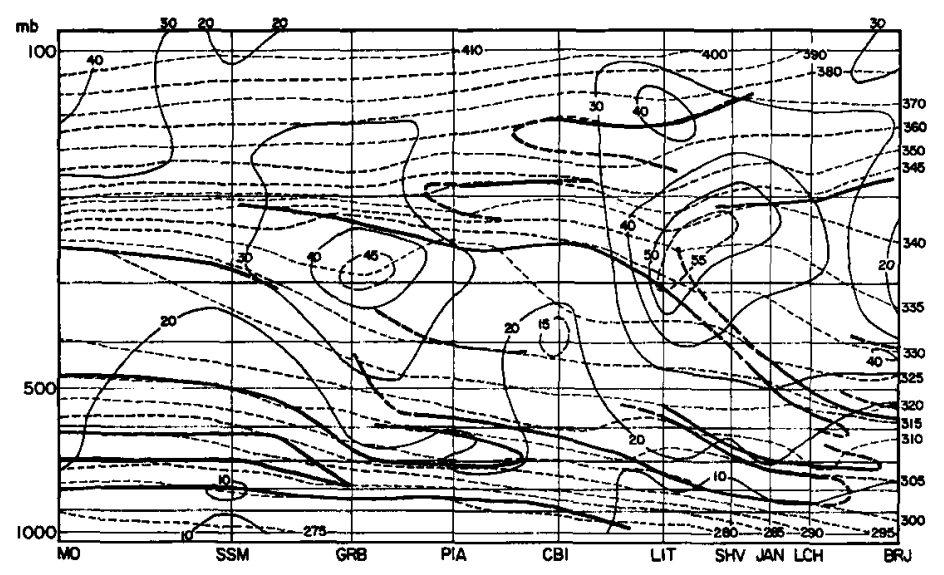

FraURE 6.-Cross section from Moosonee (MO), Ontario, to Burrwood (BRJ), La., Nov. 20, 1962, 1200 GMT. Thin solid lines represent isotachs (m/sec); thin dashed lines, potential temperatures $\left({ }^{\circ} \mathrm{K}\right)$. Stable layers and tropopauses are shown as heavy lines. Other call letters are SSM, Sault Ste. Marie; GRB, Green Bay; PIA, Peoria; CBI, Columbia; LIT, Little Rock; SHV, Shreveport; JAN, Jacksonville; and LCH, Lake Charles.

ridge above which one would normally find the STJ (Palmén, 1954; Krishnamurti, 1961a, 1961b). Thus, even from a superficial inspection of the upper flow pattern it would seem unorthodox to call the southern one of the two jet branches a STJ even though it occurs at rather high levels. According to figure 6, which shows a cross section from Moosonee, Ontario, to Burrwood, La., for Nov. 20,1962, $1200 \mathrm{GMT}$, the southern jet branch is found near Shreveport, La., slightly below the 200-mb level. Highest velocities are found between potential temperatures of $330^{\circ}$ and $340^{\circ} \mathrm{K}$. The northern jet branch is located in this cross section near Green Bay, Wis., near $300 \mathrm{mb}$, and at a potential temperature of approximately $325^{\circ} \mathrm{K}$. 


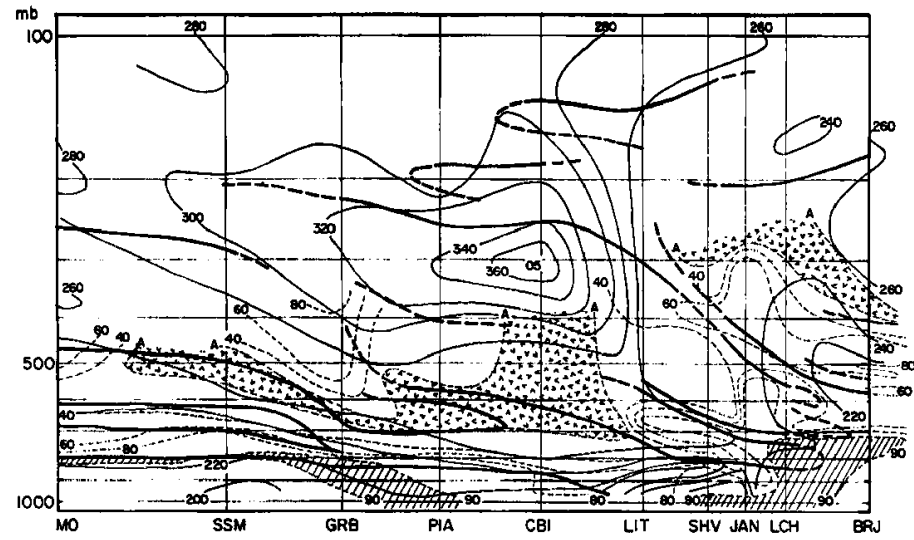

FiguRe 7.-Same cross section as in figure 6, except solid lines are isogons (degrees); dashed lines, relative humidity (percent); motorboating regions, shaded and marked by letter " $\mathrm{A}$ "; and regions with humidity $>90$ percent are crosshatched.

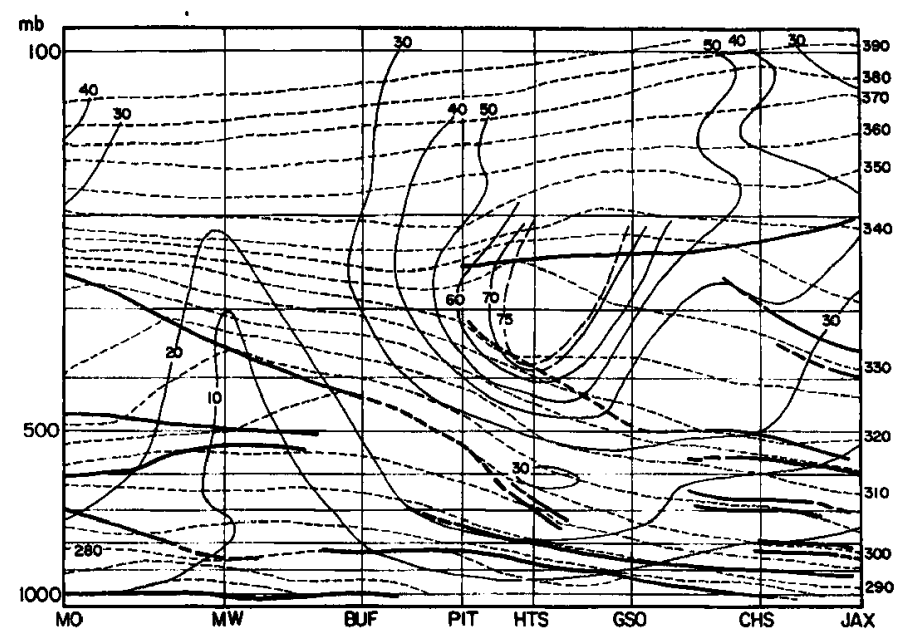

Figdre 8.-Cross section from Moosonee (MO), Ontario, to Jacksonville (JAX), Fla., Nov. 20, 1962, 1200 GMT. Thin solid lines represent isotachs $(\mathrm{m} / \mathrm{sec})$; thin dashed lines, potential temperatures at $5^{\circ} \mathrm{K}$ intervals $\left(10^{\circ} \mathrm{K}\right.$ in stratosphere). Stable layers and tropopauses are shown as heavy lines. Other call letters are $\mathrm{MW}$, Maniwaki; CHS, Charleston.

Marked baroclinicity prevails throughout the troposphere underneath both jet branches. A frontal zone appears especially well established beneath the southern branch. This fact further disqualifies this jet stream as STJ, for which one normally finds the baroclinicity confined to the upper troposphere above the $400-$ or $500-\mathrm{mb}$ level.

Figure 7 , showing relative humidity and wind direction in the same cross section as figure 6 , indicates dry subsiding air within the shear line (i.e., the region with northerly winds) between the two jet branches. This conforms to Hsieh's (1950) model of shear-line development. Moist air and precipitation are observed beneath the southern jet branch. Some low-level cloudiness and occasional reports of snowfall spread beneath the northern jet branch. A "motorboating" layer of dry air with its base

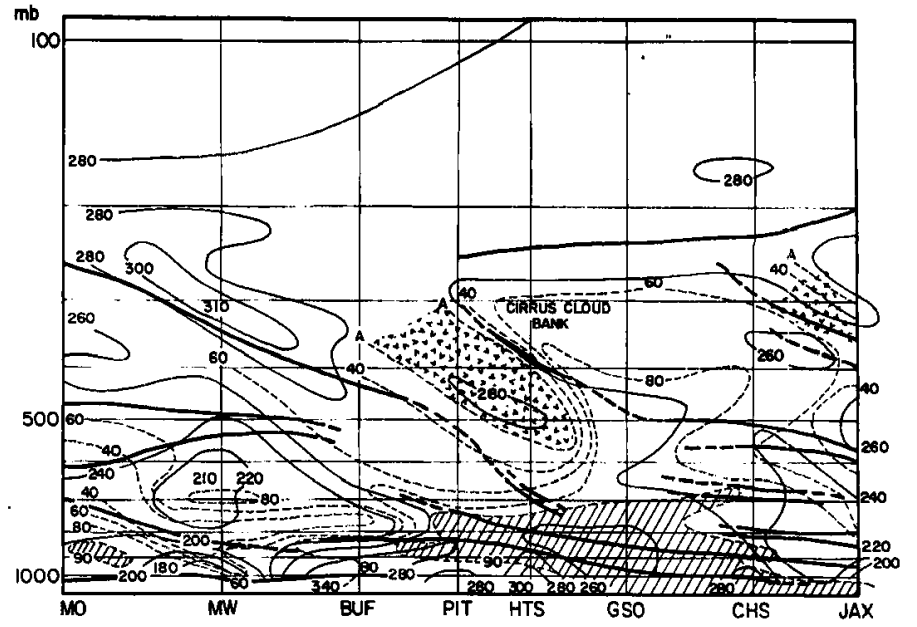

Figure 9.-Same section as in figure 8, except solid lines are isogons (degrees); dashed lines, relative humidity (percent); motorboating regions shaded and marked by letter "A"; and regions with humidity $>90$ percent are crosshatched.

at 10,000 to $15,000 \mathrm{ft}$ sharply defines the vertical extent of any cloudiness in this region.

Although the TIROS-V mosaic (fig. 3) does not reach far enough west to fully corroborate humidity conditions depicted in figure 7, we may assume that cirrus clouds, if present, broke off slightly to the north of Shreveport, remaining on the anticyclonic side of the southern branch as postulated by Kadlec's model. Cloud heights in this region should be at, or below, the 30,000-ft level.

From there on eastward, the edge of the cirrus band follows the axis of lowest temperatures on the 250-mb surface. Warm advection in this region would indicate rising motions, especially since the local temperature changes in this area were close to zero.

Figure 8 shows wind speeds and potential temperatures in a cross section from Moosonee (MO), Ontario, to Jacksonville (JAX), Fla. This cross-sectional plane intersects the main jet maximum in a region where the two jet branches attain their closest proximity. The core of strongest winds lies between $330^{\circ}$ and $340^{\circ} \mathrm{K}$, which corresponds to the potential temperature range at which the southern jet branch appeared in figure 6 . The jet core in figure 8 is located at Huntington (HTS), W. Va., somewhere between 300 and $200 \mathrm{mb}$. Although the wind measurement at Huntington terminates below $300 \mathrm{mb}$ with $78 \mathrm{~m} \mathrm{sec}^{-1}$, one may infer from the strong cyclonic and anticyclonic shears to the north and the south of this station that winds reached still higher velocities at higher levels. Extrapolating these shears, as well as the vertical wind profile of Huntington, one would arrive at maximum winds perhaps in excess of 100 $\mathrm{m} \mathrm{sec}-1$, located near the $200-\mathrm{mb}$ level and close to the $330^{\circ}$ to $340^{\circ} \mathrm{K}$ isentropic layer characteristic of the southern jet branch.

In figure 9, which shows wind directions and relative humidities in the same cross section as figure 8 , we notice 


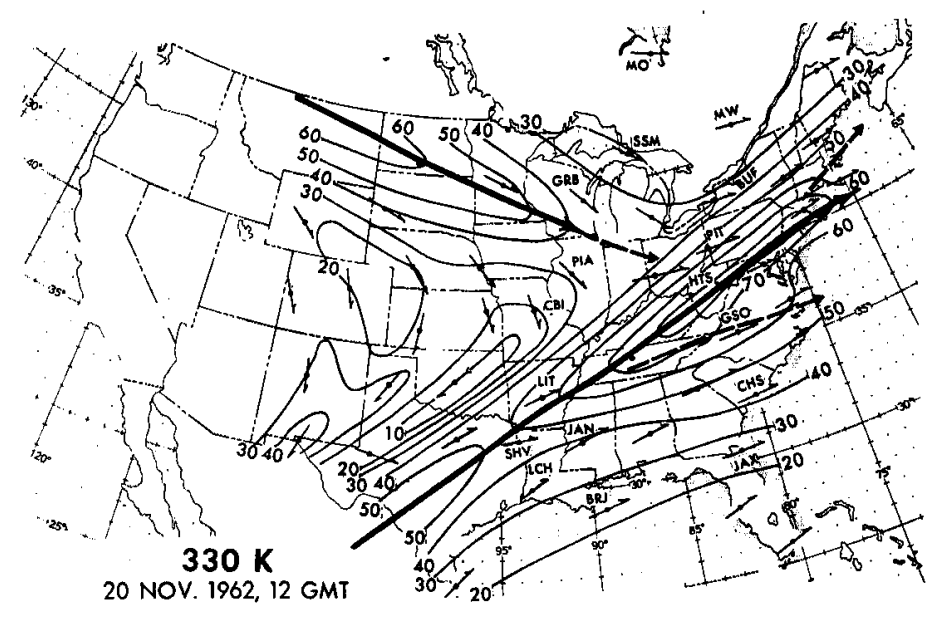

FigdRe 10.- $330^{\circ} \mathrm{K}$ isentropic surface. Isotachs are given in $\mathrm{m} / \mathrm{sec}$ and wind directions by arrows.

that moist air extends to relatively high levels at, and southeast of, the jet core. The cirrus shield observed in figure 3 ends abruptly on the anticyclonic side of a broad and diffuse baroclinic zone which contains motorboating humidity reports. This dry air is indicative of subsidence from stratospheric levels through the "tropopause gap." Such motions have been observed in conjunction with transport of radioactive debris from the stratosphere to the troposphere (Reiter, $(1963 b)$. In view of the evidence from figures 4,6 , and 8 and the orientation of the cirrus edge in figure 3 , it appears that at least in this case the subsidence of stratospheric air within the baroclinic frontal zone beneath a jet stream is most effective in regions where two well-developed jet branches are merging. Corroboration still has to be sought from similar cases.

Figure 10 shows wind velocities on the $330^{\circ} \mathrm{K}$ isentropic surface. The southwesterly jet-stream axis lies at about this level. The cirrus cloud deck observed in figure 3 lies at and just below this level and south of the baroclinic zone (fig. 9). The shadow band coincides with the main jet axis as analyzed on this surface. Rising motion in the region of upper tropospheric clouds agrees well with flow towards lower pressure values even though the motion cannot be considered strictly adiabatic because of release of latent heat of sublimation. This effect may be considered small, however, at levels close to the tropopause.

Unfortunately, the present quality of humidity measurements in the atmosphere does not allow an estimate in figures 8 and 9 of how far upwards the separation between dry and moist air underneath the jet stream continues. The dry region within the "jet-stream front" of figure 9 seems to be associated with potential temperatures between $305^{\circ}$ and $325^{\circ} \mathrm{K}$. Twelve hours earlier (November 20, $0000 \mathrm{GMT}$ ) the sounding at International Falls, Minn., indicated a stable layer below the tropopause $(216 \mathrm{mb})$ with potential temperatures ranging from $319.5^{\circ} \mathrm{K}$ near the base of this layer $(278 \mathrm{mb})$ to $336^{\circ} \mathrm{K}$ at tropopause level. Highest winds in this layer were reported to be 35 $\mathrm{m} \mathrm{sec}^{-1}$ from $331^{\circ}$. From the 250 -mb chart (not shown), it appears that this stable layer over International Falls was subject to strong cyclonic shears in the northwesterly jet branch under nearly straight-flow conditions. The potential vorticity $(P)$ in this layer may be estimated from the expression $P=Q \cdot \partial \theta / \partial p$, where $Q$ is absolute vorticity, $\theta$ is potential temperature, and $p$ is pressure. Measuring from that 250-mb chart and from the sounding for International Falls, values of $Q \simeq-\frac{\Delta V}{\Delta n}+f=20.27$ $\times 10^{-5} \mathrm{sec}^{-1}$ and $\Delta \theta / \Delta p=16^{\circ} / 60 \mathrm{mb}$, we arrive at $P \simeq 54$ $\times 10^{-\theta} \mathrm{gm}^{-1} \mathrm{~cm} \mathrm{sec} \mathrm{deg}$.

A trajectory along the $320^{\circ} \mathrm{K}$ isentropic surface, starting in this stable region over International Falls on November 20 at 0000 GMT, terminates $12 \mathrm{hr}$ later close to the cross-sectional plane of figure 8 near Pittsburgh. We may estimate a radius $(R)$ of streamline curvature in this region of approximately $6^{\circ}$ of latitude. The absolute vorticity is approximately $Q=(V / R)-\frac{\Delta V}{\Delta n}+f \simeq 37.4 \times 10^{-5}$ $\sec ^{-1}$, and the potential vorticity within the stable and strongly shearing layer slightly south of Pittsburgh (fig. 8) is $P=50.7 \times 10^{-9} \mathrm{gm}^{-1} \mathrm{~cm} \mathrm{sec} \mathrm{deg.}$

From the cross section in figure 6 , it is evident that the southwesterly jet branch is associated with higher potential temperatures than the northwesterly one. If we have assumed $320^{\circ} \mathrm{K}$ to be characteristic of the stable layer underneath the latter one of the two jets, potential temperatures of $330^{\circ}$ to $340^{\circ} \mathrm{K}$ would characterize the upper portions of the stable layer underneath the southwesterly jet more properly. Values of potential vorticity in this layer between Huntington (HTS), W. Va., and Pittsburgh (PIT), Pa., are $59 \times 10^{-9} \mathrm{gm}^{-1} \mathrm{~cm}$ sec deg. Trajectories suggest that air parcels at this location and level originated near Midland, Tex., $12 \mathrm{hr}$ earlier. Potential vorticities in the Midland (MAF) area between $330^{\circ}$ and $340^{\circ} \mathrm{K}$ at 0000 GMT on Nov. 20, 1962, were approximated $44 \times 10^{-9} \mathrm{gm}^{-1} \mathrm{~cm}$ sec deg. Thus, high values of potential vorticity appear to be reasonably well conserved between Midland (MAF) and Pittsburgh (PIT) within the stable layer underneath the southwesterly jet core. A similar conservation of potential vorticity holds for the flow in the stable layer underneath the northwesterly jet core, as has been demonstrated before. Both jets merge south of Pittsburgh (fig. 8), giving rise to one, broad baroclinic zone with high potential vorticity. Since the southerly jet is associated with higher potential temperatures than the northwesterly one, it evidently is overriding the latter. By this, the vertically elongated jet core shown in figure 8 is generated.

Relative humidities beneath the northern jet branch in figure 7 are quite high. Nevertheless, adiabatic descent of approximately $80 \mathrm{mb}$ would cause motorboating measurements like those in figure 9. Assuming a steady state, a descent of at least $50 \mathrm{mb}$ is indicated from Green Bay, Wis., to Pittsburgh along the $330^{\circ} \mathrm{K}$ isentropic surface. In agreement with the earlier case study by Reiter and Nania (1964), the dry air in the jet-stream front (fig. 9) 
TABLe 1.-Sounding data, San Antonio, Tex., Nov. 20, 1962, 0000 GMT

\begin{tabular}{c|c|c|c}
\hline \hline$p(m b)$ & $T\left({ }^{\circ} \mathrm{C}\right)$ & $\theta\left({ }^{\circ} \mathrm{K}\right)$ (estimated) & Relative humidity (\%)* \\
\hline 300 & -37.3 & 333.5 & A 22 \\
400 & -21.1 & 328.0 & 29 \\
436 & -15.6 & 326.0 & 41 \\
500 & -12.1 & 318.5 & $\mathrm{~A} 16$ \\
532 & -11.4 & 313.8 & 24 \\
618 & -3.7 & 309.0 & 81 \\
\hline
\end{tabular}

" A" indicates maximum possible values under motorboating conditions.

is associated with a slight northerly component of flow, while the moist air containing the observed cirrus clouds shows a southerly wind component. Thus, the subsidence of air from the northern jet branch underneath the southern branch is corroborated by a rotation component of the wind vector, $\Delta / \mathbf{v} \Delta z>0$.

On the anticyclonic side of the strong jet maximum shown in figure 10, trajectories of constant potential vorticity are more difficult to estima te because of the high wind speeds prevailing near the jet core and because of values of absolute vorticity approaching zero. Nevertheless, we may consider the flow conditions at the $330^{\circ} \mathrm{K}$ isentropic surface on November 20, 1200 GMT (fig. 10), near Greensboro (GSO), N.C. According to figure 9, this isentropic level should be characteristic of the flow in, or near, the cirrus cloud bank. Figure 8 indicates this level at a pressure of approximately $290 \mathrm{mb}$.

The anticyclonic shear on the $330^{\circ} \mathrm{K}$ surface shown in figure 9 , together with the nearly straight flow conditions, and $\Delta \theta / \Delta p \simeq 6.25 \times 10^{-5} \mathrm{gm}^{-1} \mathrm{~cm} \mathrm{sec}{ }^{2} \mathrm{deg}$ evident from figure 8 , yields a potential vorticity of $1.94 \times 10^{-9} \mathrm{gm}^{-1} \mathrm{~cm}$ sec deg in this region and at this level. This value is considerably smaller than the one previously computed for the descending air on the cyclonic side of the PFJ. It is characteristic of tropospheric air masses on the anticyclonic side of the jet stream.

The air mass found near Greensboro, N.C., and Washington, D.C., on November 20, $1200 \mathrm{GMT}$, at the $330^{\circ} \mathrm{K}$ isen tropic surface may be traced backwards to the Mexican border near Del Rio and San Antonio, Tex., at 0000 GMT on the same day. The San Antonio sounding of November 20,0000 GMT, shows the characteristics in table 1 .

Conditions at Del Rio are similar. From the data given in table 1, it appears that a dry and stable layer extends between approximately $314^{\circ}$ and $326^{\circ} \mathrm{K}$. Above this layer moist conditions prevail again.

If air with 41-percent relative humidity were lifted dry adiabatically from $436 \mathrm{mb}$ until saturation is reached (at approximately $370 \mathrm{mb}$ ), and from there on moist adiabatically to the $290-\mathrm{mb}$ level, it would acquire a potential temperature there of $330^{\circ} \mathrm{K}$. This is in excellent agreement with cloud and moisture conditions actually

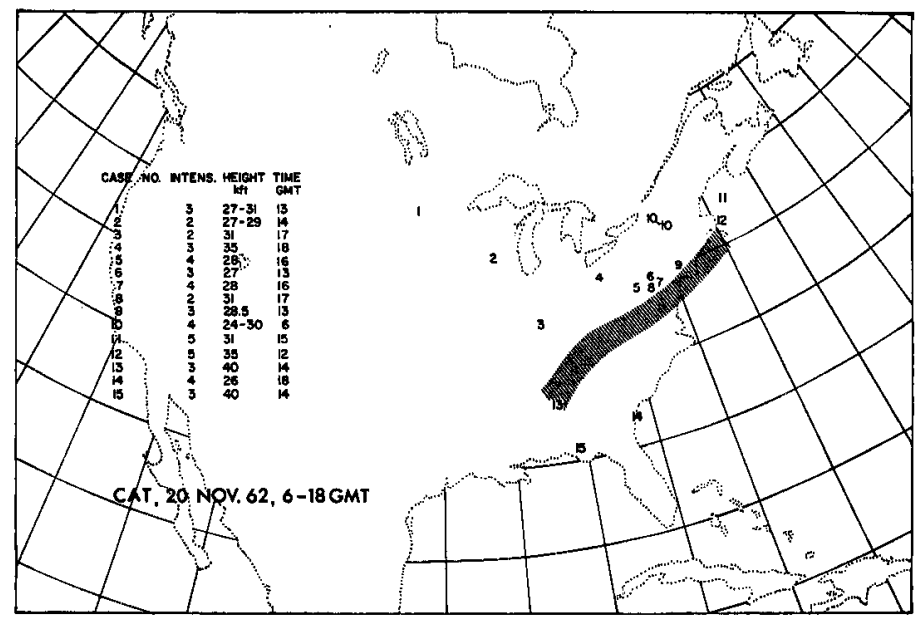

Figure 11.-CAT occurrence over the eastern United States, Nov. $20,1962,0600 \mathrm{GMT}$ to $1800 \mathrm{GMT}$. The north edge of the hatched band corresponds to the shadow band observed by TIROS VI.

found near Greensboro, N.C., on November 20, 1200 GMT (figs. 8 and 9 ).

Unfortunately, horizontal wind shear conditions and streamline curvature are not defined well enough over the Mexican border to permit accurate estimates of potential vorticity. Stability in the moist layer under consideration over San Antonio is estimated as $\Delta \theta$ $/ \Delta p \simeq 5.5 \times 10^{-5} \mathrm{gm}^{-1} \mathrm{~cm} \mathrm{sec}{ }^{2} \mathrm{deg}$. This value is very close to the one found $12 \mathrm{hr}$ later over Greensboro.

Reiter and Nania (1964) have commented on the fact that "clear-air turbulence" (CAT) is frequently found in regions where two jet branches are "crossing over," generating a large vertical wind-shear vector (see also Reiter, 1964). Figure 11 contains CAT reports over the eastern United States within $\pm 6 \mathrm{hr}$ of map time. A number of these reports lie in the region where winds are backing with height (fig. 9). Although the thermal stability in this region is considerable (fig. 8), the prevailing vector-wind shears produced by $\Delta V / \Delta z$ and $\Delta$ (direction)/ $\Delta z$ obviously provide the supply of turbulent kinetic energy observed in CAT (Reiter and Burns, 1965).

A number of moderate to severe CAT reports lie close to the shadow band reported by Oliver et al. (1964). All of them obviously occur at levels lower than the cirrus cloud deck, except for one report at $35,000 \mathrm{ft}$ near Nantucket Island.

\section{CONCLUSIONS}

Shadow bands in TIROS cloud photographs, such as the one observed by Oliver et al., between two merging jet branches may be used to illustrate the deficiencies of standard jet-stream nomenclature:

1) Two well-established jet branches, apparently approaching each other and departing again judging from 250-mb analyses, may not necessarily meet all characteristic criteria of PFJ and STJ. Especially the criteria that baroclinicity underneath the STJ is confined 
to the upper troposphere and that low tropospheric frontal systems should be absent are not satisfied in the present case even though the southern jet occurs at a level (ca. $200 \mathrm{mb}$ ) normally assigned to STJ. One, therefore, should exercise caution in applying established nomenclature. The frontal system over the Gulf of Mexico (fig. 5) suggests that the southwesterly jet branch may actually be the remnant of an old PFJ (Reiter, 1961, 1963a).

2) Even the Canadian three-front, three jet-stream model does not account for the flow from one jet branch into the other described in the foregoing study and illustrated by the cirrus cloud deck which terminates abruptly in a well-defined edge. The implications from such crossover flow may be of importance in stratospherictropospheric mass exchange, as well as in estimates of large-scale eddy transport processes. It should make some difference, for instance, whether one considers the axis of the STJ meandering around the hemisphere (Krishnamurti, 1961a, 1961b) as an approximate streamline or whether one allows for a direct inflow of air from the STJ into the regions occupied by the PFJ. More research is needed for quantitative estimates of such possible effects.

3) Ever since Schaefer's study (1953), much discussion has appeared in meteorological literature about the correlation and the relative position of cloud forms to jet streams. No unified solution to this problem can be offered as yet, and in view of the complex vertical-motion patterns around jet streams, the existence of a simple solution seems questionable. At least in the present case, though, a seeming discrepancy can be resolved: if one had hoped that cirrus clouds, when present, would remain on the anticyclonic side of jet streams, the crossing over of such cloud banks from one jet branch to another, as observed by Oliver et al., and by Kadlec, apparently was not in strict accordance with expectations. However, if jet axes are constructed as outlined in this paper, allowing the southern jet branch to cross over the northern one, the observed high-level cloudiness remains on the anticyclonic side of the flow.

4) The observation of shadow bands depends on favorable satellite attitude and sun angle. By incorporating satellite radiation data one will be able to detect similar high- and low-level cloud distributions, even in the absence of shadow bands.

\section{ACKNOWLEDGMENT}

This report has been prepared with support under Grant E-10-68G from the National Environmental Satellite Center, ESSA.

\section{REFERENCES}

Galloway, J. L., "Three-Front Model: Its Philosophy, Nature, Construction and Use," Weather, Vol. 13, No. 1, London, Jan. 1958, pp. 3-10.

Galloway, J. L., "The Three-Front Model and the Thunderstorm," Weather, Vol. 18, No. 2, London, Feb. 1963, pp. 42-54.

Hsieh, Y.-P., "On the Formation of Shear Lines in the Upper Atmosphere," Journal of Meteorology, Vol. 7, No. 6, Dec. 1950, pp. 382-387.

Kadlec, P. W., "An In-Flight Study of the Relation Between Jet Streams, Cirrus, and Wind Shear Turbulence," Final Report, Contract Cwb-10356, Eastern Airlines Meteorology Department, Atlanta, Ga., June 1963, 48 pp.

Kadlec, P. W., "A Study of Flight Conditions Associated With Jet Streams, Cirrus, Atmospheric Temperature Change, and Wind Shear Turbulence," Final Report, Contract No. Cwb-10674, Eastern Airlines Meteorology Department, Atlanta, Ga., June $1964,45 \mathrm{pp}$.

Krishnamurti, T. N., "The Subtropical Jet Stream of Winter," Journal of Meteorology, Vol. 18, No. 2, Apr. 1961a, pp. 172-191.

Krishnamurti, T. N., "On the Role of the Subtropical Jet Stream of Winter in the Atmospheric General Circulation," Journal of Meteorology, Vol. 18, No. 5, Oct. $1961 b$, pp. 657-670.

McIntyre, D. P., "The Canadian 3-Front, 3-Jet Stream Model," Geophysica, Vol. 6, Nos. 3-4, Helsinki, 1958, pp. 309-323.

Oliver, V. J., Anderson, R. K., and Ferguson, E. W., "Some Examples of the Detection of Jet Streams from TIROS Photographs," Monthly Weather Review, Vol. 92, No. 10, Oct. 1964, pp. 441-448.

Palmén, E. H., "Utber die atmosphärischen Strahlströme," (Atmospheric Jet Streams), Meteorologische Abhandlungen, Vol. 2, No. 3, Freie Universität, Berlin, 1954, pp. 35-50.

Reiter, E. R., Meteorologie der Strahlströme, (Meteorology of the Jet Streams), Springer-Verlag, Vienna, 1961, $473 \mathrm{pp}$.

Reiter, E. R., Jet Stream Meteorology, University of Chicago Press, $1963 a, 515$ pp.

Reiter, E. R., "A Case Study of Radioactive Fallout," Journal of Applied Meteorology, Vol. 2, No. 6, Dec. 1963b, pp. 691-705.

Reiter, E. R., "Clear Air Turbulence Models and Forecasting for Project TOPCAT, Second Phase, September 1-30, 1963," Project TOPCAT Meteorological Reports, Department of Meteorology, University of Melbourne Press, Australia, 1964, pp. III 1-26.

Reiter, E. R., and Burns, A., "Atmospheric Structure and ClearAir Turbulence," Atmospheric Science Technical Paper No. 65, Colorado State University, Fort Collins, June 1965, $13 \mathrm{pp}$.

Reiter, E. R., Lang, H., Mook, R., and Wendler, G., "Analyse dreier Forschungsflüge des 'Project Jet Stream," " (Analysis of Three Research Flights of 'Project Jet Stream'), Archiv für Meteorologie, Geophysik und Bioklimatologie, Ser. A, Vol. 12, No. 2, Vienna, Feb. 1961, pp. 183-221.

Reiter, E. R., and Nania, A., "Jet-Stream Structure and Clear-Air Turbulence (CAT)," Journal of Applied Meteorology, Vol. 3, No. 3. June 1964, pp. 247-260.

Schaefer, V. J., "Cloud Forms of the Jet Stream," Tellus, Vol. 5, No. 1, Feb. 1953, pp. 27-31.

Whitney, L. F., Jr., Timchalk, A., and Gray, T. I., Jr., "On Locating Jet Streams From TIROS Photographs," Monthly Weather Review, Vol. 94, No. 3, Mar. 1966, pp. 127-138. 